\title{
Foreword
}

\section{Challenges in This Year, Beyond the Earthquake Disaster}

\section{Tomohiko OHNO}

\section{President of IEIJ}

Chubu Electric Power Co., Inc.

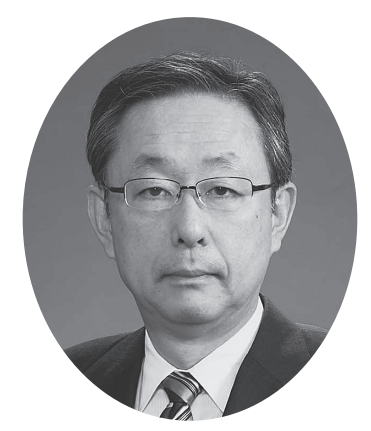

The Great East Japan Earthquake that occurred on March 11 last year and the nuclear power plant accident that arose from it caused Japan enormous damage. Even now, one year later, many people are still enduring mental and physical pain. Meanwhile, this disaster has provided an opportunity for people to become more aware of lighting.

The disaster made us realize anew another value of lighting. The Tohoku Region was hit by a major blackout over a large area immediately after the earthquake struck. The power supply was recovered, although gradually, and electric lights went on one by one in houses, which had been pitch black. Many people gave a cry of joy the moment the lights came on and brightened the inside of their houses. If you saw the smiles on their faces, you would have felt this was something more than just joy at the brightness. Many rediscovered that one electric light not only illuminates the inside of a house but also people's hearts deep down inside and that is the power to bring hopes for a bright future.

Another point to mention is the rapid increase in people's awareness of LED lighting. After the confusion of the rolling blackouts, electricity consumption restrictions were imposed on the Tohoku and Tokyo regions. The government asked the households and corporations to save power in other regions as well due to the shutdown of the nuclear power plants. This awakened people to save power. Their interest expanded beyond the locations of lighting fixtures in homes and offices to the types of fixtures used. Their interest focused on the power consumed by lighting fixtures, and LED lighting, which had not been very widespread, attracted attention at once. Energy-inefficient incandescent light bulbs were pushed to the back of the shelves at large scale electronic retailers, and LED lights, featuring the lowest power consumption, came to be displayed at the front.

We as the Illuminating Engineering Institute of Japan need to promote our activities in line with social needs in view of these changes in social interest in lighting, which we hope could lead to the development of the Institute. Accordingly, we will carry out activities with the emphasis on two points:

1. Diffusion of solid-state lighting including LED lighting

2. Active provision of information about lighting to society

For this first item, working toward the standardization of solid-state lighting is important before anything else. Solid-state lighting including LED lighting, which received immediate attention because of its low power consumption, is undeniably still under development. Its superiority in terms of energy saving performance, service life, color rendering and diversity will undoubtedly bring LEDs and other solid-state lighting to the forefront of lighting in the near future. However, there still are no safety and performance standards in place and, in the unlikely event of an accident caused by poor-quality products, the public's distrust of LEDs will increase at once, which may put a stop to their diffusion. For this reason, we must positively move forward with standardization. Ultimately, we intend to create new illumination studies that incorporate devices, software technologies and designs.

For the second item, we plan to offer correct information on how to ensure illumination in times of disaster based on our knowledge and experience about power-saving measures and lighting. Last summer, many people took the wrong power-saving measures due to a lack of knowledge about lighting. For the better understanding on the measures we proposed the Emergency Measures for Saving Lighting Power (Lighting Power Saving during Peak Hours) which we believe to have contributed to the public benefit. We consider it is important to continue actively providing such information in the future. 